\title{
SYNTHESIS AND APPLICATION OF TWO NEW IONIC LIQUIDS IN THE EXTRACTION OF CELLULOSE FROM BOUGAINVILLEA SPECTABILIS
}

\author{
DIANA L. CAMPA-GUEVARA, NOHRA V. GALLARDO-RIVAS, \\ ANA M. MENDOZA-MARTÍNEZ, ULISES PÁRAMO-GARCÍA, LUCIANO AGUILERA-VÁZQUEZ \\ and REINALDO D MARTÍNEZ-OROZCO
}

Tecnológico Nacional de México/I. T. Cd. Madero, Centro de Investigación en Petroquímica, Prol. Bahía de Aldhair y Av. de las Bahías, Parque de la Pequeña y Mediana Industria, 89600, Altamira, Tamaulipas, México

๔Corresponding author: N. V. Gallardo, nohvigari@itcm.edu.mx

Received May 7, 2020

Cellulose is a natural polymer formed by chains of polysaccharide carbohydrates. Traditional processes for extraction of cellulose are expensive and require solvents with high ionic strength and stringent conditions. In this paper, we propose the extraction of cellulose from Bougainvillea spectabilis by using a traditional procedure, such as alkaline and acidic hydrolysis extraction, as well as the Vieira extraction method with the aid of two ionic liquids (ILs), with the purpose of using a solvent that allows reducing the harmful impact on the environment and human health. The obtained fibrous materials were analyzed by FTIR spectroscopy and the gravimetric method. According to gravimetric measurements, the results show an efficiency of $99.3 \%$ for the proposed extraction method and of $42.97 \%$ for acid hydrolysis. These results show that the proposed method allows adequate extraction using ionic solvents.

Keywords: cellulose, Bougainvillea spectabilis, ionic liquids, cellulose extraction method, acid hydrolysis

\section{INTRODUCTION}

Natural lignocellulose is the most abundant material on the earth and it is composed of cellulose, hemicellulose and lignin..$^{1-4}$ Cellulose is one of the most abundant biopolymers, it represents the majority of terrestrial biomass and is commonly used as the main constituent in conventional paper. ${ }^{5,6}$ Cellulose is the main component of the cell wall of plants formed by linear molecules with a tendency to form fibers, which provide consistency and stiffness to plants. ${ }^{7-9}$

Due to its attractive mechanical properties and stability in various solvents, it has generated a growing scientific interest, considering its abundance and low cost as a raw material. However, cellulose technology requires the extraction and processing of this natural polymer from primary sources, using techniques that have changed very little since the beginning of the modern chemical industry, since cellulose and its derivatives can substitute as a source for various chemical compounds. ${ }^{10-13}$

The potential use of cellulose has not been fully exploited yet, because of the traditional use of petroleum-based polymers, and also because of the limited common solvents in which cellulose is easily soluble. ${ }^{14}$ Conventional dissolution processes of cellulose are often difficult or expensive, and require the use of solvents with high ionic strength and in relatively stringent conditions. ${ }^{15-17}$ With the increase in industrial pollution and the consequent government regulations, the need to implement "green" processes to avoid contamination with organic solvents, using renewable sources is becoming increasingly notable.

The effectiveness of existing methods for dissolving and extracting cellulose can be significantly improved with the availability of suitable solvents. The use of ionic solvents as a replacement for conventional organic solvents in chemical, biochemical and separation processes has been demonstrated. ${ }^{18}$ In addition, a wide and varied range of ionic solvents can be used to provide greater control and flexibility in the processing methodology. Therefore, lignoce- 
llulose fractionation and component activation are considered the first challenge towards a competitive bio-economy in terms of materials, chemicals and bioenergy production. This paper proposes the use of two ionic liquids in the extraction of cellulose.

\section{EXPERIMENTAL}

Materials

For the extraction of cellulose, fibers of Bougainvillea spectabilis were obtained from waste resulting from the shrub itself, after eliminating traces of bark or remains of other agents. The chemicals: cellulose (powder $\geq 97 \%$ ), 1-bromooctane (99\%), 1bromodecane $\quad(98 \%), \quad$ 1-methylimidazole (ReagentPlus®, 99\%), sodium hydroxide (ACS reagent, $\geq 97.0 \%) 0.1 \mathrm{M}$, sulfuric acid ACS reagent, 95.0-98.0\% $\quad(60 \% \quad$ w/w $), \quad$ 1,2-dichlorobenzene (ReagentPlus®, 99\%), acetonitrile (Anh., 99.8\%), nitrogen $(99.99 \%$ INFRA, purity level 4) and potassium bromide (FT-IR grade, $\geq 99 \%$ ) were purchased from Sigma Aldrich, México.

\section{Synthesis of 1-methyl-3-octylimidazole bromide (Br1M3OIm) and 1-methyl-3-decylimidazole bromide (Br1M3DIm)}

The ionic liquids, 1-methyl-3-octylimidazole bromide (Br1M3OIm) and 1-methyl-3-decylimidazole bromide (Br1M3DIm) were synthesized under very mild conditions by the Menshutkin reaction. ${ }^{19-21} 1$ Methylimidazole and 1-alkyl bromide were used as acquired, since the purities of the reagents were greater than 97\%, according to Sigma-Aldrich. For the synthesis process, $0.5 \mathrm{~mol}$ of 1-methylimidazole and $100 \mathrm{~mL}$ of toluene were placed in a balloon flask, equipped with a serpentine and a magnetic stirrer. The reaction was carried out in an inert nitrogen atmosphere and an ice bath. The mixture was stirred for one hour, then an excess of 1-bromooctane $(0.55$ mol) was slowly added drop by drop using a funnel, keeping the agitation constant and the atmosphere inert. The reaction continued, heating the system up to $75{ }^{\circ} \mathrm{C}$ for 24 hours (Fig. 1). To remove the excess 1 alkyl bromide, it was washed twice with acetonitrile $(100 \mathrm{~mL})$. The remaining acetonitrile was removed by heating under vacuum at $70{ }^{\circ} \mathrm{C}$ for 12 hours. The sample was cooled to room temperature and the product obtained was the IL of interest. ${ }^{22-27}$ Some authors recommend that the reagents be purified to eliminate impurities that appear in ionic liquids with coloration, in addition to protecting the reaction flask from light by covering it with aluminum foil. ${ }^{26,27}$

\section{1-Methyl-3-octylimidazole bromide (Br1M3OIm)}

IR (KBr) v/cm ${ }^{-1}$ 3436, 3058, 2923, 2854, 1569, 1465, 1378, 1168, 750, 620; ${ }^{1} \mathrm{H}$ NMR (400 MHz, $\left.\mathrm{CDCl}_{3}\right) \delta 10.25(\mathrm{~s}, 1 \mathrm{H}), 7.58(\mathrm{~s}, 1 \mathrm{H}), 7.40(\mathrm{~s}, 1 \mathrm{H}), 4.27$ $\left(\mathrm{t}, 2 \mathrm{H}, J 7.2 \mathrm{~Hz}, \mathrm{CH}_{2}\right), 4.08\left(\mathrm{~s}, 3 \mathrm{H}, \mathrm{CH}_{3}\right), 1.86(\mathrm{~m}, 2 \mathrm{H}$, $\left.\mathrm{CH}_{2}\right), 1.22(\mathrm{~m}, 10 \mathrm{H}), 0.81\left(\mathrm{t}, 3 \mathrm{H}, \mathrm{J} 5.9 \mathrm{~Hz}, \mathrm{CH}_{3}\right) ;{ }^{13} \mathrm{C}$ NMR $\left(101 \mathrm{MHz}, \mathrm{CDCl}_{3}\right) \delta 137.31,123.73,121.97$, 77.48, 77.16, 76.85, 50.15, 36.77, 31.67, 30.34, 29.03, $28.95,26.25,22.59,14.10$.

\section{1-Methyl-3-decylimidazole bromide (Br1M3DIm)}

IR (KBr) v/cm ${ }^{-1} 3437,3059,2925,2855,1568$, 1460, 1378, 1167, 751, 620; ${ }^{1} \mathrm{H}$ NMR (400 MHz, $\left.\mathrm{CDCl}_{3}\right) \delta 10.31(\mathrm{~s}, 1 \mathrm{H}, \mathrm{CH}), 7.55(\mathrm{~s}, 1 \mathrm{H}), 7.38(\mathrm{~s}, 1 \mathrm{H})$, $4.29\left(\mathrm{t}, 2 \mathrm{H}, J 7.2 \mathrm{~Hz}, \mathrm{CH}_{2}\right), 4.11\left(\mathrm{~s}, 3 \mathrm{H}, \mathrm{CH}_{3}\right), 1.87(\mathrm{~m}$, $\left.2 \mathrm{H}, \mathrm{CH}_{2}\right), 1.26\left(\mathrm{~m}, 14 \mathrm{H}, \mathrm{CH}_{2}\right), 0.84(\mathrm{t}, J 6.1 \mathrm{~Hz}, 3 \mathrm{H})$; ${ }^{13} \mathrm{C}$ NMR $\left(101 \mathrm{MHz}, \mathrm{CDCl}_{3}\right) \delta 137.46,123.62,121.86$, 77.45, 77.13, 76.82, 50.19, 36.80, 31.85, 30.36, 29.47, $29.39,29.26,29.02,26.28,22.68,14.16$.

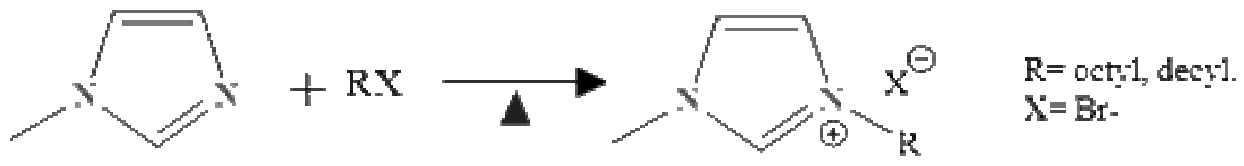

Figure 1: Synthesis route of 1-methyl-3-alkylimidazole bromide

\section{Preconditioning of Bougainvillea spectabilis fibers}

In this work, wood cuttings of Bougainvillea spectabilis were used to obtain fibers to extract cellulose. After cutting the branches to sizes of 0.5-0.7 $\mathrm{mm}$, two samples of $100 \mathrm{~g}$ each were weighed and crushed to obtain small fibers, which were placed in an oven at $75{ }^{\circ} \mathrm{C}$ for 24 hours to remove the moisture contained in the plant.

\section{Depigmentation of preconditioned fibers by alkaline treatment \\ In this step, $45 \mathrm{~g}$ of the dry sample ( 3 samples of 15 g each) was reacted with $0.1 \mathrm{M} \mathrm{NaOH}$ to remove pigmentation (chlorophyll, xanthophylls). The sample}

was weighed and added to a $0.1 \mathrm{M} \mathrm{NaOH}$ solution, then heated to $45{ }^{\circ} \mathrm{C}$ for 3 hours under constant stirring. Followig the treatment with $\mathrm{NaOH}$, the sample was washed with distilled water until the filtrate was clear and the $\mathrm{pH}$ was neutral. The washed fibers were dried in an oven at $50{ }^{\circ} \mathrm{C}$ for 72 hours. Finally, the obtained samples were weighed and compared with the initial weight.

\section{Acid hydrolysis method}

Fibers obtained from the alkaline treatment (3 samples of $3 \mathrm{~g}$ each) were weighed and added to 200 $\mathrm{mL}$ of $60 \% \mathrm{H}_{2} \mathrm{SO}_{4} \mathrm{w} / \mathrm{w}$ aqueous solution, at $45{ }^{\circ} \mathrm{C}$ for 30 minutes, under constant stirring. Subsequently, the 
solution was allowed to cool for 24 hours before filtering and washing. The washes were carried out with distilled water and the obtained samples were left to dry for 24 hours at $75{ }^{\circ} \mathrm{C}$.

\section{Extraction method with organic solvent}

In this method, 1,2-dichlorobenzene (ODCB) with the boiling point of $180-183{ }^{\circ} \mathrm{C}$ was used as organic solvent. ODCB is a liquid that goes from colorless to yellow and with a characteristic odor. It can be absorbed by inhalation, through the skin or ingestion, it is irritating to eyes, skin and respiratory tract. The substance may affect the central nervous system and liver, and its exposure may cause decreased alertness. For this method, 3 samples of $3 \mathrm{~g}$ each of alkali treated samples were used. The sample was added to $150 \mathrm{~mL}$ of 1,2-dichlorobenzene, then, it was filtered with distilled water until a clear liquid was obtained. The sample was dried for 24 hours at $75^{\circ} \mathrm{C}$.

\section{Cellulose extraction method with ionic liquids}

a) 1-Methyl-3-octylimidazole bromide

(Br1M3OIm): 3 samples of $3 \mathrm{~g}$ each of dried Bougainvillea spectabilis samples treated with $0.1 \mathrm{M}$ $\mathrm{NaOH}$ were used. $50 \mathrm{~mL}$ of $\mathrm{Br} 1 \mathrm{M} 3 \mathrm{OIm}$ was used and heated at $160{ }^{\circ} \mathrm{C}$ for 3 hours with constant stirring. Br1M3OIm is a very viscous amber liquid similar to honey. The sample was washed with ethyl alcohol until obtaining a diaphanous filtration. Then, the sample was dried for 24 hours at $75{ }^{\circ} \mathrm{C}$. Water was not used as it can interact with the ionic liquid and it would not be possible to recover it later.

b) 1-Methyl-3-decylimidazole bromide (Br1M3DIm): 3 samples of $3 \mathrm{~g}$ each of dried Bougainvillea spectabilis samples treated with $0.1 \mathrm{M}$
$\mathrm{NaOH}$ were used. $50 \mathrm{~mL}$ of $\mathrm{Br} 1 \mathrm{M} 3 \mathrm{DIm}$ was used and heated at $80{ }^{\circ} \mathrm{C}$ and $160{ }^{\circ} \mathrm{C}$ for 3 hours with constant stirring. At the end of the heating, the sample was filtered and washed with ethyl alcohol. The filtrate was preserved to later recover the ionic liquid and reuse it. The sample was dried for 24 hours at $75^{\circ} \mathrm{C}$.

\section{Characterization by infrared spectroscopy (FTIR)}

FITR spectroscopy was used to analyze and compare the fibers obtained by the different methods described above. $\mathrm{KBr}$ tablets (potassium bromide) were prepared from each of them, and for comparative purposes, commercial cellulose was used as reference. $^{11}$ To obtain the FTIR spectra, a PerkinElmer spectrophotometer Model Spectrum 100 was used, with 32 scans, in the range of $4000-400 \mathrm{~cm}^{-1}$ at a resolution of $4 \mathrm{~cm}^{-1}$. KBr pellets $(5 \mathrm{mg}$ of sample for $100 \mathrm{mg}$ of $\mathrm{KBr}$ ) were prepared. Three measurements were made for each sample and the average value was considered.

\section{RESULTS AND DISCUSSION}

The analyses of the applied methods for the extraction of cellulose fibers from Bougainvillea spectabilis are presented below.

\section{Preconditioning analysis of Bougainvillea spectabilis fibers}

Because the sample was easily burned when dried at $100{ }^{\circ} \mathrm{C}$ (a), drying temperature was changed to $75{ }^{\circ} \mathrm{C}$ (b), as the drying temperature could affect the obtained sample and the time of cellulose extraction (Fig. 2). ${ }^{28}$

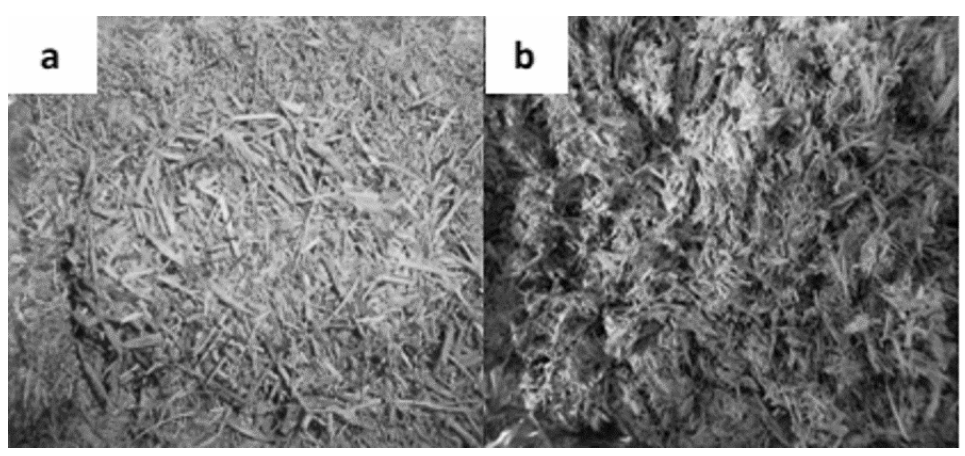

Figure 2: Dry sample at (a) $100{ }^{\circ} \mathrm{C}$ and (b) $75^{\circ} \mathrm{C}$

\section{Analysis of fibers obtained by alkaline treatment}

Figure 3 shows the obtained pigment-free fibers after performing the alkaline treatment on preconditioned fibers, and after the filtering and drying process. These fibers were used to obtain cellulose by different methods: acid hydrolysis, the scallop method with 1,2-dichlorobenzene as organic solvent, and the scallop method with ionic solvent. Br1M3OIm and Br1M3DIm were used as ionic liquids in this last method, and the obtained fibers were analyzed by infrared spectroscopy and optical microscopy. ${ }^{29}$ 


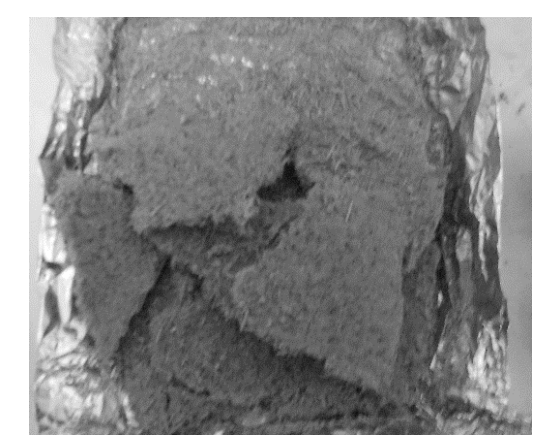

Figure 3: Washed and dried sample

FT-IR analysis of samples obtained by different chemical methods

The characteristic bands of cellulose were identified in the infrared spectra. The presence of signals between 3500 and $3200 \mathrm{~cm}^{-1}$ is due to the vibration frequency of the $-\mathrm{OH}$ group with hydrogen bonds (intramolecular and intermolecular), the band at $3000 \mathrm{~cm}^{-1}$ corresponding to the vibration frequency of the $\mathrm{CH}$ group, the band at $1600 \mathrm{~cm}^{-1}$ is attributed to the bending vibration of $-\mathrm{OH}$, the band between 900 and $1300 \mathrm{~cm}^{-1}$ indicates in-plane bending of the $-\mathrm{OH}$ group, the band between 1100 and 1200 $\mathrm{cm}^{-1}$ corresponds to $\mathrm{C}-\mathrm{O}-\mathrm{C}$ asymmetric stretching, and the band at $1100 \mathrm{~cm}^{-1}$ is due to $\mathrm{C}-$ O stretching. ${ }^{30,31}$

In the spectrum of commercial cellulose (Figs. 4, 5, 6 and 7), the presence of a strong intensity band due to $-\mathrm{OH}$ vibration is observed at 3345 $\mathrm{cm}^{-1}$ and the bending of the -OH group at 1638 $\mathrm{cm}^{-1}$. The $\mathrm{C}-\mathrm{O}-\mathrm{C}$ asymmetric stretching is observed at $1163 \mathrm{~cm}^{-1}$ and the $\mathrm{C}-\mathrm{O}$ vibration band at $1060 \mathrm{~cm}^{-1}$. The small band at $2901 \mathrm{~cm}^{-1}$ is assigned to the stretching vibration of the $-\mathrm{CH}$ group. Also, the asymmetric $-\mathrm{CH}_{2}$ and symmetric $-\mathrm{CH}_{3}$ vibration stretching is observed at $1431 \mathrm{~cm}^{-}$ ${ }^{1}$ and $1373 \mathrm{~cm}^{-1}$, respectively.

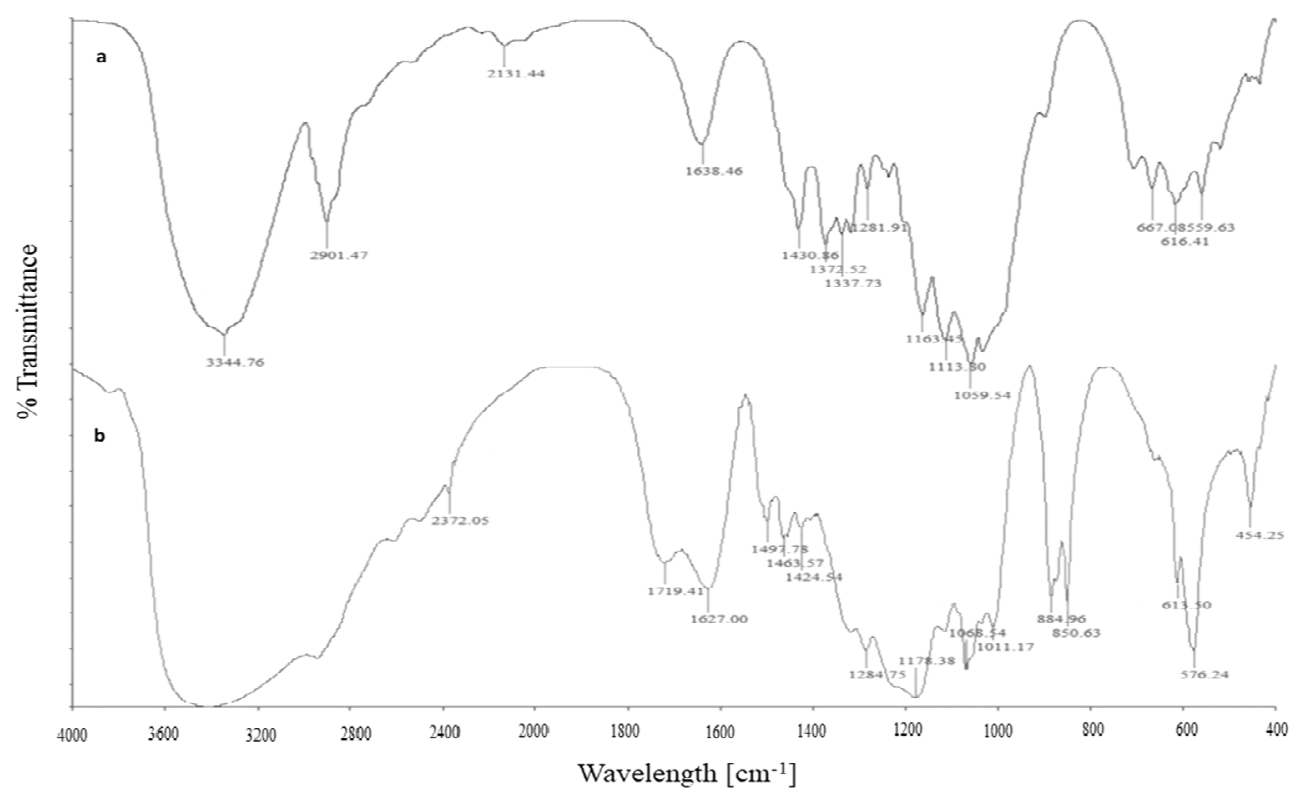

Figure 4: Infrared spectra of commercial cellulose (a) and of cellulose obtained by acid hydrolysis (b) 


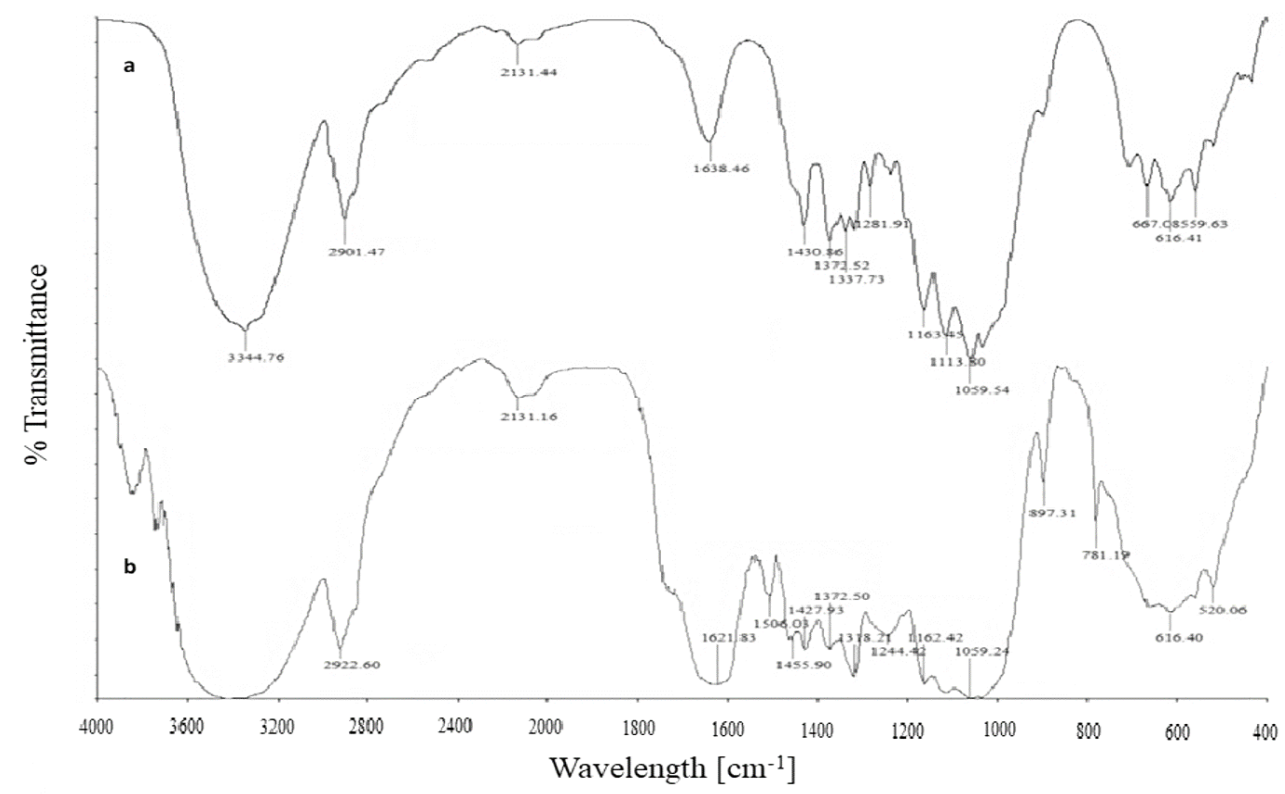

Figure 5: Infrared spectra of commercial cellulose (a) and of cellulose obtained by the Vieira method with an organic solvent (b)

Analysis of fibers obtained by acid hydrolysis

In the spectrum of cellulose obtained by acid hydrolysis (Fig. 4b), the broad band of strong intensity observed at approximately $3500 \mathrm{~cm}^{-1}$ corresponds to the stretching vibration of the $-\mathrm{OH}$ group, with the bending of $-\mathrm{OH}$ at $1627 \mathrm{~cm}^{-1}$. The asymmetric stretching of $\mathrm{C}-\mathrm{O}-\mathrm{C}$ bonds is notable at $1178 \mathrm{~cm}^{-1}$ and the $\mathrm{C}-\mathrm{O}$ bond is observed at $1068 \mathrm{~cm}^{-1}$. The stretching vibration of

\section{Analysis of fibers extracted with an organic solvent}

Figure 5 (b) shows the spectrum of cellulose extracted by the Vieira method ${ }^{32}$ with an organic solvent. In this spectrum, we can see the -OH stretching at approximately $3400 \mathrm{~cm}^{-1}$ as a broad band of strong intensity and the bending of $-\mathrm{OH}$ is exhibited at $1621 \mathrm{~cm}^{-1}$. The asymmetric C-O-C stretching is localized at $1162 \mathrm{~cm}^{-1}$ and the $\mathrm{C}-\mathrm{O}$ bond is noted at $1059 \mathrm{~cm}^{-1}$. $-\mathrm{CH}$ stretching is shown as a peak of medium intensity at $2922 \mathrm{~cm}^{-}$ 1. The vibration at $1455 \mathrm{~cm}^{-1}$ and $1427 \mathrm{~cm}^{-1}$ corresponds to asymmetric $-\mathrm{CH}_{3}$ and $-\mathrm{CH}_{2}$ bending; while the symmetric bending of $-\mathrm{CH}_{3}$ is observed at $1372 \mathrm{~cm}^{-1}$ and $1318 \mathrm{~cm}^{-1}$. The bands at $897 \mathrm{~cm}^{-1}, 731 \mathrm{~cm}^{-1}$ and $616 \mathrm{~cm}^{-1}$ indicate that there is a substituted benzene ring; this can mean that the solvent (1,2-dichlorobenzene) adhered to the fibers, possibly requiring a more thorough washing.
$-\mathrm{CH}$ is shown as a weak peak at $2372 \mathrm{~cm}^{-1}$. The vibration at $1463 \mathrm{~cm}^{-1}$ and $1424 \mathrm{~cm}^{-1}$ is assigned to the asymmetric bending of $-\mathrm{CH}_{3}$. The bands at $885 \mathrm{~cm}^{-1}$ and $850 \mathrm{~cm}^{-1}$ indicate the bending of $=\mathrm{CH}_{2}$ bonds, and the peak at $576 \mathrm{~cm}^{-1}$ is due to the bending of $\mathrm{C}=\mathrm{C}$ bonds. This result may indicate that the cellulose was partially removed when the acid medium was used as a solvent.

\section{Analysis of fibers obtained by scallop method with ionic solvent}

Figure 6 (b) shows the spectrum of the cellulose obtained by the Vieira method with Br1M3OIm at $160{ }^{\circ} \mathrm{C}$. The $-\mathrm{OH}$ stretching is noted approximately between $3400 \mathrm{~cm}^{-1}$ and 3500 $\mathrm{cm}^{-1}$, and the $-\mathrm{OH}$ bending at $1630 \mathrm{~cm}^{-1}$. The asymmetric C-O-C stretching is localized at 1165 $\mathrm{cm}^{-1}$, the peaks at $1034 \mathrm{~cm}^{-1}$ and $1059 \mathrm{~cm}^{-1}$ indicate the $\mathrm{C}-\mathrm{O}$ vibration. $-\mathrm{CH}$ stretching is indicated by two peaks at $2857 \mathrm{~cm}^{-1}$ and 2927 $\mathrm{cm}^{-1}$, respectively. Also, the asymmetric $-\mathrm{CH}_{3}$ bending is observed at $1428 \mathrm{~cm}^{-1}$ and $1463 \mathrm{~cm}^{-1}$, and the symmetric bending of $-\mathrm{CH}_{3}$ at $1373 \mathrm{~cm}^{-1}$. The peak at $621 \mathrm{~cm}^{-1}$ indicates $\mathrm{C}-\mathrm{Br}$, which may be due to the solvent used. Some of the bands, such as those corresponding to $-\mathrm{OH}$ and $-\mathrm{CH}$, precede the bands from the spectrum of Br1M3OIm. Therefore, the washing of the sample should be improved after extraction.

The FTIR spectra of the cellulose fibers extracted by the Vieira method using Br1M3DIm 
DIANA L. CAMPA-GUEVARA et al.

at $160{ }^{\circ} \mathrm{C}$ and at $80{ }^{\circ} \mathrm{C}$ were compared with that of commercial cellulose in Figure 7. $-\mathrm{OH}$ stretching can be seen at $3417 \mathrm{~cm}^{-1}$ for the fibers obtained with Br1M3DIm at $80{ }^{\circ} \mathrm{C}$, and at 3350 $\mathrm{cm}^{-1}$ for those achieved at $160{ }^{\circ} \mathrm{C}$. $-\mathrm{OH}$ bending is located at $1638 \mathrm{~cm}^{-1}$ for the fibers extracted at $80{ }^{\circ} \mathrm{C}$, and at $1630 \mathrm{~cm}^{-1}$ for those obtained at 160
${ }^{\circ} \mathrm{C}$. The asymmetric $\mathrm{C}-\mathrm{O}-\mathrm{C}$ stretching band is observed at $1163.71 \mathrm{~cm}^{-1}$ for the cellulose obtained with $\mathrm{Br} 1 \mathrm{M} 3 \mathrm{DIm}$ at $80{ }^{\circ} \mathrm{C}$, and at 1163 $\mathrm{cm}^{-1}$ for that achieved at $160{ }^{\circ} \mathrm{C}$. Meanwhile, the vibration of the $\mathrm{C}-\mathrm{O}$ bond was localized at approximately $1059 \mathrm{~cm}^{-1}$ for both temperatures.

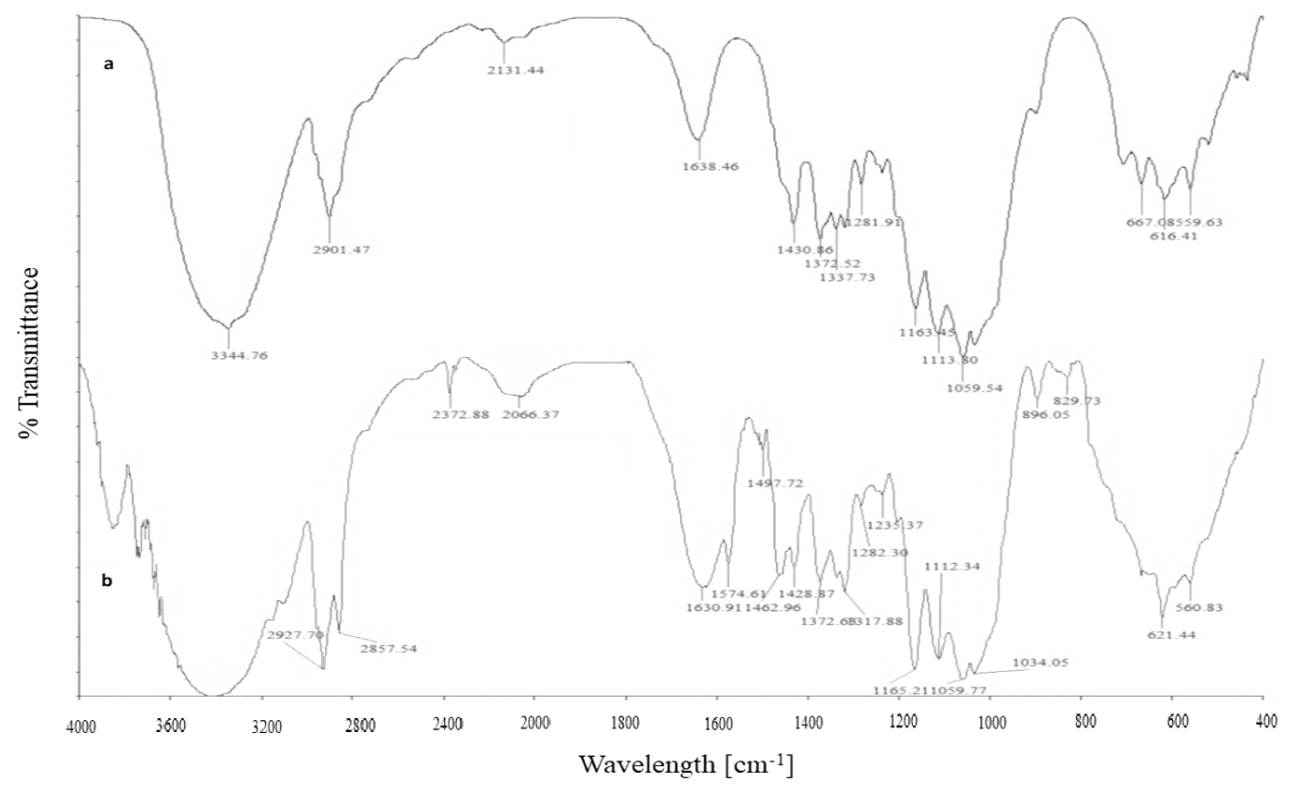

Figure 6: Infrared spectra of commercial cellulose (a) and of cellulose obtained by the Vieira method with Br1M3OIm (b)

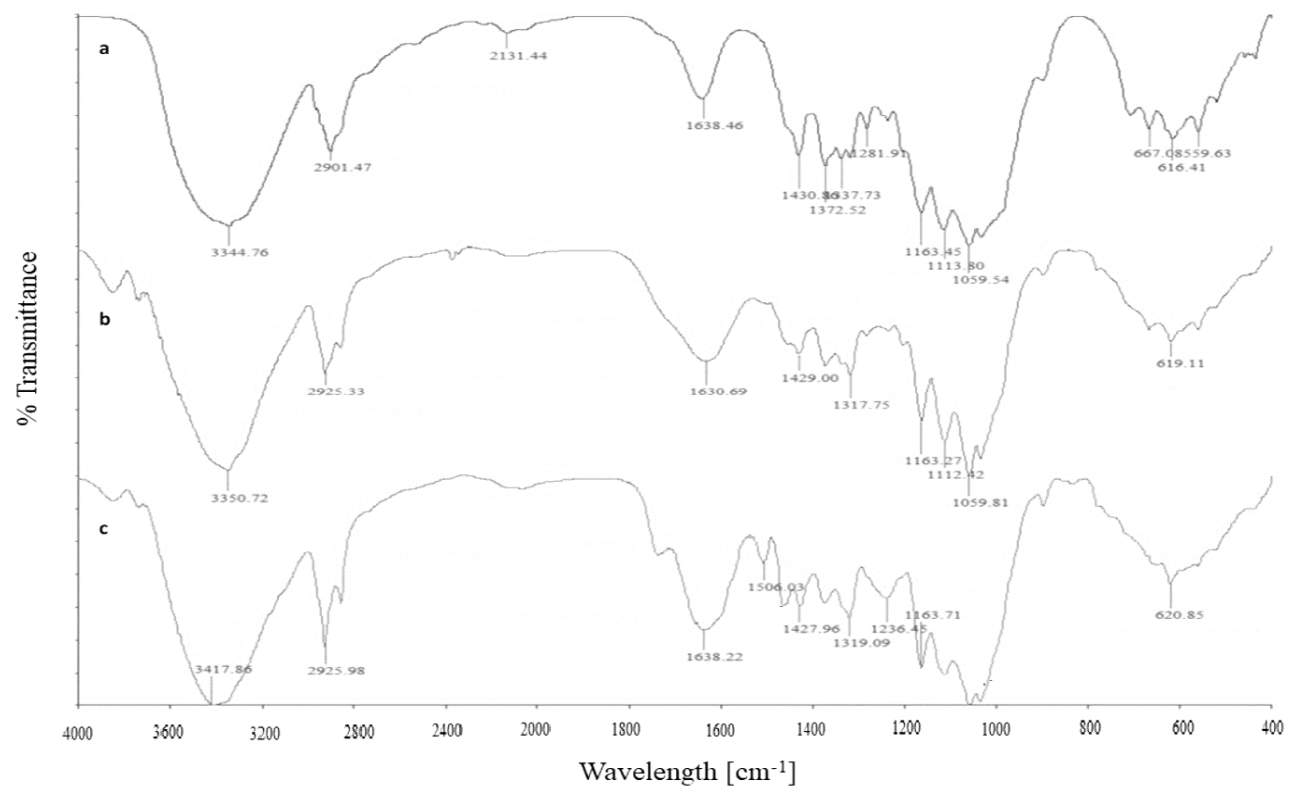

Figure 7: Infrared spectra of commercial cellulose (a) and of cellulose obtained by the Vieira method with Br1M3DIm at $160{ }^{\circ} \mathrm{C}(\mathrm{b})$ and $75^{\circ} \mathrm{C}(\mathrm{c})$ 


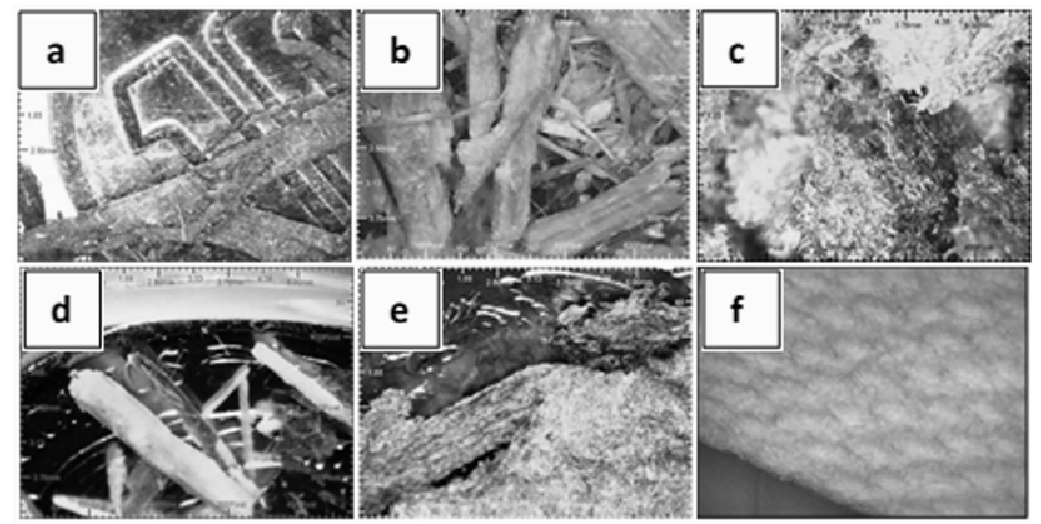

Figure 8: Micrographs of cellulose fibers obtained a) by acid hydrolysis at $75^{\circ} \mathrm{C}$, b) with 1,2-dichlorobenzene, c) with $\mathrm{Br} 1 \mathrm{M} 3 \mathrm{OIm}$ at $160{ }^{\circ} \mathrm{C}$, d) with $\mathrm{Br} 1 \mathrm{M} 3 \mathrm{DIm}$ at $75^{\circ} \mathrm{C}$, e) with $\mathrm{Br} 1 \mathrm{M} 3 \mathrm{DIm}$ at $160^{\circ} \mathrm{C}$, f) white cellulose (commercial)

It is further observed that the - $\mathrm{CH}$ stretching is located at $2925 \mathrm{~cm}^{-1}$ and $2925 \mathrm{~cm}^{-1}$, respectively; the asymmetric $-\mathrm{CH}_{3}$ bending is noted at 1427 $\mathrm{cm}^{-1}$ for the cellulose obtained with Br1M3DIm at $80{ }^{\circ} \mathrm{C}$, and at $1429 \mathrm{~cm}^{-1}$ for that obtained at 160 ${ }^{\circ} \mathrm{C}$; while the symmetric $-\mathrm{CH}_{3}$ bending is observed at $1319 \mathrm{~cm}^{-1}$ and $1317 \mathrm{~cm}^{-1}$. The peaks at $620 \mathrm{~cm}^{-1}$ and $619 \mathrm{~cm}^{-1}$ indicate the C-Br bond. Similarly, to the previous spectrum, this may be due to the ionic liquid, considering that bands such as $-\mathrm{OH}$ and $-\mathrm{CH}$ are placed before the bands of the spectrum of Br1M3DIm.

\section{Optical microscopy analysis of samples obtained by different chemical methods}

Figure 8 (a) shows the micrograph of cellulose fibers obtained by acid hydrolysis, revealing dark colored and approximately $6 \mathrm{~mm}$ long fibers. The cellulose fibers obtained with the organic solvent ODBC (Fig. 8b) present bright yellow fiber color, without changes in fiber size, compared to alkali treated fibers. The cellulose extracted with Br1M3OIm (Fig. 8c) shows small agglomerated fibers.

As regards the cellulose extracted with Br1M3DIm at $80{ }^{\circ} \mathrm{C}$ (Fig. 8d), clear fibers were obtained, of the same size as the sample achieved by the alkaline treatment. Figure 8 (e) shows the cellulose fibers obtained with Br1M3DIm at 160 ${ }^{\circ} \mathrm{C}$, which are dark colored, but lighter than those obtained with $\mathrm{Br} 1 \mathrm{M} 3 \mathrm{OIm}$ at $160{ }^{\circ} \mathrm{C}$. The fibers extracted by Br1M3OIm and Br1M3DIm at 160 ${ }^{\circ} \mathrm{C}$ are the ones that resemble the most closely the fibers of commercial cellulose, except for the coloration. This is explained by the solvent used and by the fact that no bleaching solution was used. Figure 8 (f) shows the commercial cellulose fibers, which are white. ${ }^{17,33}$

\section{Evaluation of the effect of the solvent on treated Bougainvillea spectabilis}

Table 1 shows the mass of Bougainvillea spectabilis (clean and dry) used for each of the systems. In addition, the table lists the average percentages of the fibers obtained in each case (triple experimentation). In the case of the first batch, alkaline treatment was carried out as a pretreatment, for eliminating traces of contaminants, as well as the characteristic pigments of the plant (Figs. 2 and 3). For the treatment in acidic medium, an average percentage of treated mass of $42.5 \pm 0.8 \%$ was obtained, representing a high mass loss. This is explained by the fact that the acid degrades the samples, which has been also confirmed by the FTIR analysis (Fig. 4b).

For the samples treated by the Vieira method, ${ }^{32}$ with the use of solvent (1.2dichlorobenzene), the average mass percentage obtained was in the order of $96.8 \pm 1.8 \%$. This solvent is commonly used in cellulose extraction; however, the cleaning process of the final product is arduous and not always efficient. Despite the high mass percentages obtained, the FTIR study (Fig. 5b) showed traces of the solvent used, which is a contaminant. 
Table 1

Mass percentages of Bougainvillea spectabilis before and after the treatments

\begin{tabular}{|c|c|c|c|}
\hline Chemical method & $\begin{array}{l}\text { Initial mass } \\
(\mathrm{g})\end{array}$ & $\begin{array}{l}\text { Final mass } \\
(\mathrm{g})\end{array}$ & $\begin{array}{c}\text { Average treated mass } \\
\text { obtained }(\%)\end{array}$ \\
\hline Alkaline treatment & 15 & 12.23 & $81.5 \pm 1.5$ \\
\hline Acid hydrolysis $\left(75^{\circ} \mathrm{C}\right)$ & 3 & 1.28 & $42.5 \pm 0.8$ \\
\hline Vieira method with organic solvent $\left(75^{\circ} \mathrm{C}\right)$ & 3 & 2.91 & $96.8 \pm 1.8$ \\
\hline Vieira method with $\operatorname{Br} 1 \mathrm{M} 3 \mathrm{OIm}\left(160^{\circ} \mathrm{C}\right)$ & 3 & 1.39 & $46.4 \pm 0.4$ \\
\hline Vieira method with $\operatorname{Br} 1 \mathrm{M} 3 \operatorname{Dim}\left(160^{\circ} \mathrm{C}\right)$ & 3 & 1.42 & $47.2 \pm 1.1$ \\
\hline Vieira method with Br1M3DIm $\left(75^{\circ} \mathrm{C}\right)$ & 3 & 2.97 & $98.8 \pm 0.5$ \\
\hline
\end{tabular}

The use of ionic liquids is a viable alternative as they are chemically stable when modifying the operating temperature. Table 1 shows the results obtained when using the two ionic liquids studied at $75^{\circ} \mathrm{C}$ and $160^{\circ} \mathrm{C}$. When using a temperature of $160{ }^{\circ} \mathrm{C}$, a percentage mass of $46.4 \pm 0.4 \%$ and $47.2 \pm 1.1 \%$ was obtained for the fibers extracted with Br1M3Oim and Br1M3Dim, respectively. For the latter, a higher mass percentage was obtained, which can be attributed to the larger ion size of the ionic liquid. ${ }^{34,35}$ The best result was achieved using Br1M3DIm and a temperature of $75^{\circ} \mathrm{C}$, yielding a percentage mass of $98.8 \pm 0.5 \%$ (even comparing with the extraction with the traditional organic solvent). This demonstrates that ionic liquids yield higher mass percentages of extracted fibers, or in the order of those obtained with conventional organic solvents. ${ }^{36}$ This supports the major objective of this study of using ion liquids as novel solvents for cellulose extraction, as a way to decrease the temperature of the extraction process and reduce traces of solvent residues. $^{37,38}$

\section{CONCLUSION}

The present study has investigated the possibility of using two ionic liquids in the extraction of cellulose and compared the percentage mass of the fibers obtained with that achieved by other common extraction methods. As a result, it can be concluded that alkaline treatment yielded clean fibers, free of waxes and pigments characteristic of Bougainvillea spectabilis, with a mass percentage of $81.5 \pm 1.5 \%$. Depending on the solvent used in cellulose extraction, mass percentages of fibers between 42 and $98 \%$ have been obtained, the Vieira method being more efficient than acid hydrolysis $(42.5 \pm 0.8 \%$ for the latter). The application of 1 methyl-3-decylimidazole bromide (Br1M3DIm) by the Vieira method improves the extraction of fibers, reaching mass percentages of $98.8 \pm 0.5 \%$.
When lowering the extraction temperature to 75 ${ }^{\circ} \mathrm{C}$, an efficiency of $98.8 \pm 0.5 \%$ was achieved using Br1M3DIm, this value being similar to that reached with a traditional organic solvent $(96.8 \pm 1.8 \%)$. However, using an ionic liquid allows obtaining cleaner cellulose, without traces of solvents, structurally similar to commercial cellulose. An additional advantage is that ionic liquids are less toxic and can be recovered.

ACKNOWLEDGEMENTS: D. L. CampaGuevara wants to thank CONACyT-Mexico (493783/635248) for the granted doctor degree fellowship. Also, the authors acknowledge the project "Synthesis of ionic liquids for application in the extraction of lignocellulose from agricultural waste, first stage", key: 6688.18-P, financed by the Tecnológico Nacional de México, and the CIP/I. T. Cd. Madero for the support provided in the implementation of this project.

\section{REFERENCES}

1 B. C. Okeke and S. K. C. Obi, Bioresour. Technol., 47, 283 (1994), https://doi.org/10.1016/09608524(94)90192-9

2 H. Chen, "Biotechnology of Lignocellulose. Theory and Practice", Chemical Industry Press, Springer, 2014, p. 25, https://doi.org/10.1007/978-94-007-68987

3 A. Arevalo-Gallegos, Z. Ahmad, M. Asghar, R. Parra-Saldivar and H. M. Iqbal, Int. J. Biol. Macromol., $\quad 99, \quad 308 \quad$ (2017), https://doi.org/10.1016/j.ijbiomac.2017.02.097

4 A. Tursi, Biofuel Res. J., 6, 962 (2019), http:// doi.org/10.18331/BRJ2019.6.2.3

5 D. Klemm, B. Heublein, H. P. Fink and A. Bohn, Angew. Chem., 44, 3358 (2005), https://doi.org/10.1002/anie.200460587

6 B. Frka-Petesic and S. Vignolini, Nat. Photonics, 13, 365 (2019), https://doi.org/10.1038/s41566-0190448-9

7 J. Mazurek, A. Laganà, V. Dion, S. Etyemez, C. Carta et al., J. Cult. Herit., 35, 263 (2019), https://doi.org/10.1016/j.culher.2018.05.011

8 F. Rol, M. N. Belgacem, A. Gandini and J. Bras, 
Prog. Polym. Sci., 88, $241 \quad$ (2019), https://doi.org/10.1016/j.progpolymsci.2018.09.002

9 A. Sharma, M. Thakur, M. Bhattacharya, E. T. Mandal and S. Goswami, Biotechnol. Rep., 21, 316 (2019), https://doi.org/10.1016/j.btre.2019.e00316

10 D. Trache, M. H. Hussin, C. T. H. Chuin, S. Sabar, M. R. Nurul-Fazita et al., Int. J. Biol. Macrom., 93, 789

https://doi.org/10.1016/j.ijbiomac.2016.09.056

(2016),

11 C. E. Maepa, J. Jayaramudu, J. O. Okonkwo, S. S. Ray, E. R. Sadiku et al., Int. J. Pol. Anal. Charac., 20, 99

https://doi.org/10.1080/1023666X.2014.961118

(2015),

12 H. Liu, Q. Li, S. Zhang, R. Yin, X. Liu et al., J. Mat. Chem. C., 45, $12121 \quad$ (2018), https://doi.org/10.1039/C8TC04079F

13 S. Zhu, Y. Wu, Q. Chen, Z. Yu, C. Wang et al., Green Chem., $\quad 8, \quad 325 \quad$ (2006), https://doi.org/10.1039/B601395C

14 Y. Sun and J. Cheng, Bioresour. Technol., 83, 1 (2001), https://doi.org/10.1016/S0960-8524(01)002127

15 M. Ghasemi, M. Tsianou and P. Alexandridis, Bioresour. Technol., 228, $330 \quad$ (2017), https://doi.org/10.1016/j.biortech.2016.12.049

16 H. Passos, M. G. Freire and J. A. P. Coutinho, Green Chem., 16, $4786 \quad$ (2014), https://doi.org/10.1039/c4gc00236a

17 L. Neubert, J. Sunthornvarabhas, M. Sakulsombat and K. Sriroth, Cellulose Chem. Technol., 54, 301 (2020),

https://doi.org/10.35812/CelluloseChemTechnol.2020. 54.32

18 S. Zhu, J. Chem. Technol. Biotechnol., 83, 777 (2018), https://doi.org/10.1002/jctb.1884

19 X. Mu, N. Jiang, C. Liu and D. Zhang, J. Phys. Chem. A., 121, 1133 (2017), https://doi.org/10.1021/acs.jpca.6b11610

${ }_{20}$ Y. Wang, H. R. Li, T. Wu, C. M. Wang and S. J. Han, Acta Phys.-Chim. Sin., 21, 517 (2005), https://doi.org/10.3866/PKU.WHXB20050512

21 A. Singh, P. Singh and N. Goel, Struct. Chem., 25, 821 (2014), https://doi.org/10.1007/s11224-013-03484

22 J. S. Wilkes, J. A. Levisky, R. A. Wilson and C. L. Hussey, Inorg. Chem., 21, 1263 (1982), https://doi.org/10.1021/ic00133a078

23 S. A. Dharaskar, M. N. Varma, D. Z. Shende, C. K. Yoo and K. L. Wasewar, The Scientific World Journal, 2013, 1 (2013), https://doi.org/10.1155/2013/395274

24 S. G. Cull, J. D. Holbrey, K. R. Vargas-Mora, K. Seddon and G. J. Lye, Biotechnol. Bioeng., 69, 227 (2000), https://doi.org/10.1002/(SICI)10970290(20000720)69:2<227::AID-BIT12>3.0.CO;2-0

25 P. A. Z. Suarez, S. Einloft, J. E. L. Dullius, R. F. De Souza and J. Dupont, J. Chim. Phys., 95, 1626 (1998), https://doi.org/10.1051/jcp:1998103
26 P. Nockemann, K. Binnemans and K. Driesen, Chem. Phys. Lett., 415, 131 (2005), https://doi.org/10.1016/j.cplett.2005.08.128

27 Y. S. Ding, M. Zha, J. Zhang and S. S. Wang, Colloids Surf. A Physicochem. Eng. Asp., 298, 201 (2007), https://doi.org/10.1016/j.colsurfa.2006.10.063 28 L. V. Han and Y. B. Seo, Cellulose Chem. Technol., $\quad 52, \quad 741 \quad$ (2018), https://www.cellulosechemtechnol.ro/pdf/CCT9-

10(2018)/p.741-747.pdf

29 K. Labidi, M. Zrida, O. Korhonen, M. A. Borguei and A. H. Hamzaoui, Cellulose Chem. Technol., 52, 701

(2018),

https://www.cellulosechemtechnol.ro/pdf/CCT910(2018)/p.701-709.pdf

30 R. Kempaiah, G. Gurappa, R. Tomar, M. Poletto, H. L. Ornaghi Jr., Cellulose Chem. Technol., 54, 187 (2020),

https://doi.org/10.35812/CelluloseChemTechnol.2020. 54.21

31 H. Yang, R. Yan, H. Chen, D. H. Lee and Ch. Zheng, Fuel, 86, $1781 \quad$ (2007), https://doi.org/10.1016/j.fuel.2006.12.013

32 M. C. Vieira, Th. Heinze, R. Antonio and A. M. Mendoza, Cellulose, 9, 203 (2002), https://doi.org/10.1023/A:1020158128506

33 K. A. Rubinson and J. F. Rubinson, "Análisis Instrumental”, Pearson Educación S.A., Madrid, 2001

34 Y. Zhang, Z. Zhou, L. Zou and R. Chi, J. Mol. Liq., 275, 136

(2019),

https://doi.org/10.1016/j.molliq.2018.11.009

35 M. Brehm, M. Pulst, J. Kressler and D. Sebastiani, J. Phys. Chem. B, 123, 3994 (2019), https://doi.org/10.1021/acs.jpcb.8b12082

36 E. Cequier, J. Aguilera, M. Balcells and R. CanelaGarayoa, Biomass Convers. Biorefin., 9, 241 (2019), https://doi.org/10.1007/s13399-019-00400-w

37 A. N. Amalini, M. K. N. Haida, K. Imran and M. K. M. Haafiz, Mater. Chem. Phys., 221, 382 (2019), https://doi.org/10.1016/j.matchemphys.2018.09.028

38 Z. Ullah, Z. Man, A. S. Khan, N. Muhammad, H. Mahmood et al., J. Clean. Prod., 220, 620 (2019), https://doi.org/10.1016/j.jclepro.2019.02.041 